\title{
Biocompatibility of fluids for multiphase drops-in-drops microfluidics
}

\author{
Aishah Prastowo $^{1}$ - Alexander Feuerborn ${ }^{2} \cdot$ Peter R. Cook $^{2} \cdot$ Edmond J. Walsh $^{1}$
}

Published online: 5 December 2016

(C) The Author(s) 2016. This article is published with open access at Springerlink.com

\begin{abstract}
This paper addresses the biocompatibility of fluids and surfactants in the context of microfluidics and more specifically in a drops-in-drops system for mammalian cell based drug screening. In the drops-indrops approach, three immiscible fluids are used to manipulate the flow of aqueous microliter-sized drops; it enables merging of drops containing cells with drops containing drugs within a Teflon tube. Preliminary tests showed that a commonly-used fluid and surfactant combination resulted in significant variability in gene expression levels in Jurkat cells after exposure to a drug for four hours. This result led to further investigations of potential fluid and surfactant combinations that can be used in microfluidic systems for medium to longterm drug screening. Results herein identify a fluid combination, HFE-7500 and 5-cSt silicone oil $+0.25 \%$ Abil EM180, which enabled the drops-in-drops approach; this combination also allowed gene expression at normal levels comparable with the conventional drug screening in both magnitude and variability.
\end{abstract}

Edmond J. Walsh

edmond.walsh@eng.ox.ac.uk

1 Osney Thermo-Fluids Laboratory, Department of Engineering Science, University of Oxford, Osney Mead, Oxford OX2 0ES, UK

2 Sir William Dunn School of Pathology, University of Oxford, South Parks Road, Oxford OX1 3RE, UK
Keywords Biocompatibility $\cdot$ Drops-in-drops $\cdot$ Drug screening $\cdot$ Mammalian cell $\cdot$ Toxicity $\cdot$ Surfactant

\section{Introduction}

Drop-based microfluidics is expected to play an important role in drug discovery (Dittrich and Manz 2006; Dressler et al. 2014; Kang et al. 2008; Tsui et al. 2013) through increased efficiency coupled to large-scale parallelization (Gong et al. 2011; Miller et al. 2012); then many compounds in many different concentrations (Churski et al. 2012; Hong et al. 2016) can be screened in different cell types (Gao et al. 2013; Yu et al. 2009). It can also facilitate single-cell analyses (Rodriguez-Rodriguez et al. 2012). In all these cases, there would be a simultaneous reduction in volumes and cost. However, current microfluidic systems suffer from various drawbacks that are limiting wide acceptance (Sackmann et al. 2014); for example, they often contain complicated network of channels that are difficult to fabricate (Friend and Yeo 2010; Mazutis et al. 2013), they require sophisticated additional machinery (Hansen et al. 2015; Kellogg et al. 2014), and one chip design is usually limited to one specific application (Fiorini and Chiu 2005; Friend and Yeo 2010).

An alternative microfluidic method utilising a Teflon tube and fluid mechanics, rather than the more common approach of relying on the geometry of micro-scale channel networks, has recently been developed (Feuerborn et al. 2015; Walsh et al. 2016). This method exploits the interfacial tension between three or more immiscible liquids to create specific fluidic architectures. In this context, we consider the particular architecture of two aqueous 
drops engulfed within one oil drop, which is - in turn surrounded by a fluorocarbon. As a result of the liquid films surrounding drops at different points within the system, the relative velocities of the two aqueous drops can be controlled; the two drops can be forced to merge, and their contents mixed (Fig. 1).

To create the required fluidic architecture in the three-phase system, fluids must have the appropriate interfacial tensions. This can be achieved when the interfacial tension between the fluorocarbon $(\mathrm{FC})$ and the aqueous phase $\left(\gamma_{\mathrm{FC} / \mathrm{aq}}\right)$ is greater than the sum of the interfacial tension between fluorocarbon and oil $\left(\gamma_{\mathrm{FC} / \text { oil }}\right)$ plus that between oil and water $\left(\gamma_{\mathrm{oil} / \mathrm{aq}}\right)$. In other words, $\gamma_{\mathrm{FC} / \mathrm{aq}}>\gamma_{\mathrm{FC} / \mathrm{oil}}+\gamma_{\mathrm{oil} / \mathrm{aq}}$, as defined by the Neumann triangle (Chen et al. 2007; Guzowski et al. 2012). This fluidic architecture, and the mechanism that drives the merging of the two aqueous drops, are illustrated in Fig. 1. The time needed for the second drop to catch up the first one depends on the initial spacing between drops (established when the two drops first enter the tube) and their relative motion thereafter (Feuerborn et al. 2015). This relative velocity is influenced by the thickness of the fluidic film surrounding the drops, which varies with Capillary number $(\mathrm{Ca}=\eta U / \gamma$, where $\eta=$ carrier fluid viscosity and $U=$ average velocity) (Bico and Quéré 2000; Bretherton 1961).

Many fluid/surfactant combinations can be found that satisfy the Neumann triangle, and allow drops-in-drops to form and merge. However, for cell-based assays, these fluid/

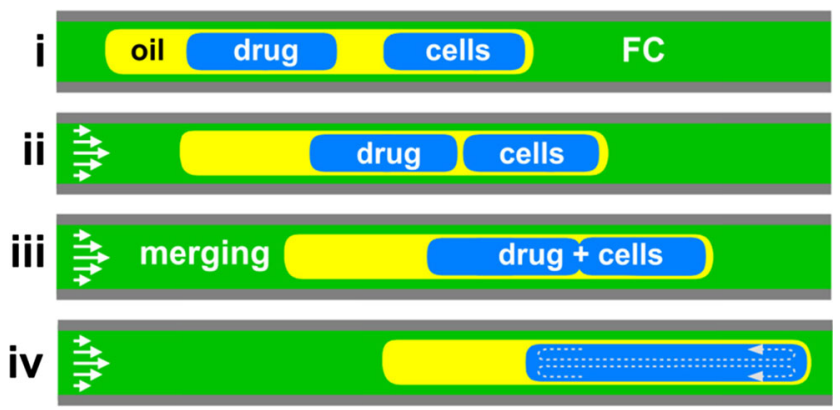

Fig. 1 Merging drops-in-drops in a Teflon tube. (i) Initial structure of two aqueous drops - which contain cells or a drug - engulfed in one oil superdrop, which is engulfed in turn in a fluorocarbon (FC). This structure spontaneously forms as the end of the tube (which is connected to a syringe pump acting in withdrawal mode, and which is pre-filled with fluorocarbon) is dipped successively into fluorocarbon, oil, growth medium containing cells, oil, growth medium containing the drug, and fluorocarbon. (ii) As a result of the oil film surrounding the aqueous drops and the parabolic laminar-flow profile, the engulfed aqueous drops containing cells moves faster than the oil. When the right-hand drop reaches the leading interface of the oil, it slows to travel at the velocity of the oil. With continued flow, the trailing left-hand drop containing the drug eventually catches up the leading one containing cells. (iii) Once the two aqueous drops touch, they merge. (iv) Internal vortices within the merged drop mix contents. This Figure was adapted from (Feuerborn et al. 2015) surfactant combinations must also be biocompatible. Surfactants are widely used in many other microfluidic dropbased systems used for biological applications, and - and as many fluid/surfactant combinations are toxic to cells (Baret 2012; Pang et al. 2006; Partearroyo et al. 1990) - biocompatibility of the liquids used is a general problem. The definition of a biocompatible environment varies within the microfluidic literature, and few studies have focused on this in a rigorous way. One measure used to claim biocompatibility is the ability to grow cells after they have been through a microfluidic device (Huang et al. 2015; Liu et al. 2009; Martin et al. 2003). However, most cells respond to a toxic environment by arresting growth, and then they may be able to "recover" from the sub-optimal environment when returned to a favourable one. Consequently, cell behaviour may differ inside and outside the device. In addition, several authors claim biocompatibility by citing a previous study using similar fluids. For example, several articles cite ref. (ClausellTormos et al. 2008) to support proliferation within drops; however, the original authors (who counted the ratio of living and dead cells) only found "some degree of proliferation within the drops". Here, we define a biocompatible environment as one in which the gene expression levels of cells in drops are comparable to those found using the same cells growing in a conventional tissue-culture flask. This definition has particular relevance in the case of a cell grown in suspension like the Jurkat cell - an immortalized line of human T lymphocytes where assessment of cell morphology is more difficult than it is with adherent cells.

Here we initially utilised the fluid/surfactant concentrations employed by others for drop-based microfluidics using cells (i.e., HFE-7500 and tetradecane + Span 80) (El Debs et al. 2012; Gu et al. 2011; Hu et al. 2015; Li et al. 2014; Martin et al. 2003; Schoeman et al. 2014) with our new approach. We used a low concentration of surfactant (i.e., $0.25 \% w / w$ Span 80 ) to minimise potential toxicity. To verify biocompatibility, we first measured levels of $5 \mathrm{~S}$ ribosomal RNA (rRNA) in Jurkat cells, as this is commonly used as a control (Tea et al. 2013). Levels (quantified using qRT-PCR) in cells from different drops were found to vary sporadically. This led us to examine the reason for this sporadic behaviour, and this was traced to the fluids/surfactants employed. We then went on to screen many fluid/ surfactant combinations to see which affected cell viability and gene expression. We found that many commonly-used combinations had negative effects on cells over periods of a few hours. We also identified a fluid/surfactant combination (i.e., HFE-7500 as carrier fluid, 5-cSt silicone oil $+0.25 \%$ Abil EM180 as separating fluid, and cell-culture media as the aqueous fluid containing cells and/or drugs) that could be used in our system and which was biocompatible (assessed by 
(a)

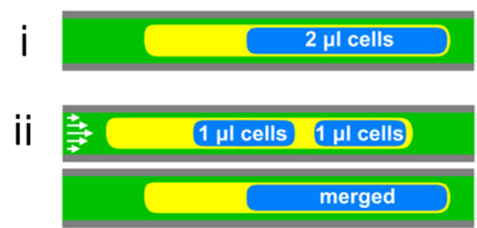

(b)

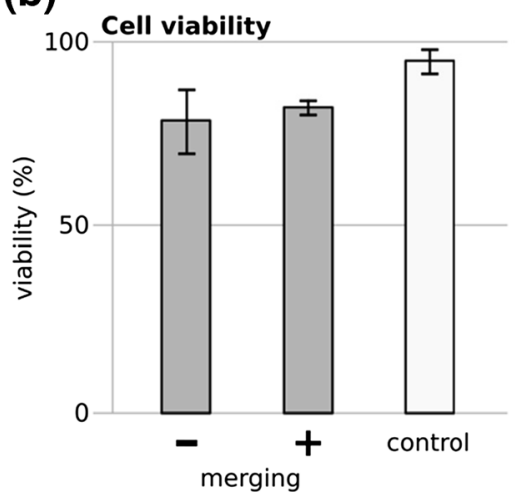

Fig. 2 Effects of tetradecane and Span 80 on cell viability and levels of 5S rRNA (Jurkat cells). (a) Two approaches used to assess viability: (i) no merging, static (2- $\mu 1$ drops in separating oil), and (ii) merging, dynamic (two 1- $\mu$ l drops were loaded, and drops merged). (b) Viability (defined as the percentage of live cells in the population assessed using trypan-blue exclusion after 'no merging' or 'merging' followed by a 4-h incubation. The three phases were growth medium, tetradecane $+0.25 \%$ Span 80, and HFE-7500. 'Control': viability after $4 \mathrm{~h}$ for the same cells grown conventionally in a 96-well plate. (c) Approach used for gene

comparing viability and expression levels using cells grown conventionally in micro-wells).

\section{Experimental methods}

\subsection{Interfacial tension measurement}

The interfacial tension between two immiscible fluids was measured using a commercial instrument (First Ten Angstroms) employing the pendant-drop method. Fluid with higher density was loaded in a syringe, a small drop was formed at the tip of the needle, and the drop was immersed in the second fluid contained in a transparent polystyrene cuvette. The interfacial tension was calculated using the manufacturer's software, a length scale (i.e., the width of the needle tip measured with a micrometre), and fluid density.

\subsection{Cell preparation}

Jurkat or EL4 (mouse lymphoblast) cells were cultured routinely in flasks in RPMI-1640 supplemented with $10 \%$ fetal bovine serum and $1 \%$ penicillin and streptomycin. They were used at $500 \mathrm{cells} / \mu \mathrm{l}$ for cell-viability assays (allowing cells to (c)

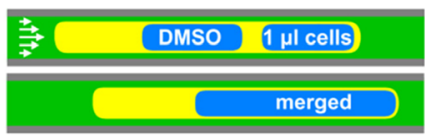

(d)

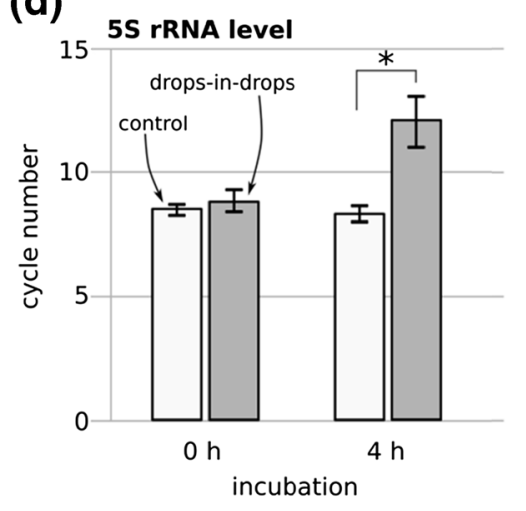

expression analysis. A drop containing cells was merged with another containing DMSO (the drug carrier). (d) Levels of 5S rRNA (assessed using qRT-PCR; a low cycle number reflects high levels of 5S rRNA). Cells were either taken into tubes and ejected immediately (' $0 \mathrm{~h}$ ') or incubated in tubes for $4 \mathrm{~h}$. 'Drops-in-drops': cells in the dynamic threephase system (HFE-7500, growth medium, and either tetradecane + $0.25 \%$ Span 80). 'Control': the same cells grown conventionally in 96well plate. Error bars: \pm standard deviation, *: significantly different (twosample t-test, $p<0.05 ; n$ (control) $=3, n$ (drops-in-drops $)=7$ )

grow for up to $48 \mathrm{~h}$ ), or 2000 cells/ $\mu \mathrm{l}$ for drug-screening tests (for $4 \mathrm{~h}$ tests).

\subsection{Fluid and surfactant biocompatibility test}

Different biocompatibility tests with different surface-tovolume ratios between aqueous drop and separating fluid were undertaken by overlaying the aqueous layer containing cells with fluid in a 96-well plate (Fig. 3 a(i)) and using a Teflon tube containing aqueous drops in two- or three-phase systems (Fig. 3 b(i), Fig. 3 c(i)).

The initial screen involved $150 \mu$ separating fluid and cells in the same well of a 96-well plate (Fig. 3 $\mathrm{a}(\mathrm{i})$ ); the non-adherant cells sediment under gravity to sit on the bottom of the well, or - if the separating fluid is the densest - on the interface between the two liquids. After incubating the plate at $37^{\circ} \mathrm{C}$ in $5 \% \mathrm{CO}_{2}$, the percentage of live cells was determined using trypan-blue exclusion and a hemocytometer after mixing equal volumes of cell solution and $0.4 \%$ trypan blue.

The fluids that had no effect on the viability in the initial screen were tested (Fig. 3 b(i)) by withdrawing drops into a Teflon tube (bore $560 \mu \mathrm{m}$ ) connected to a syringe pump 
(Harvard Ultra). The tube was filled with test fluid, $1 \mu$ drops of cell solution were withdrawn into the tube at a flow rate of $2-5 \mathrm{ml} / \mathrm{h}$, and the tube sealed at both ends and incubated at $37^{\circ} \mathrm{C}$ in $5 \% \mathrm{CO}_{2}$ for up to $48 \mathrm{~h}$. Viability was assessed as before using trypan-blue exclusion by ejecting fluid from the tube at a flow rate of $2 \mathrm{ml} / \mathrm{h}$ until 10 drops were deposited into a drop of equal volume of trypan blue.

Biocompatibility was next tested using a static three-phase system in a Teflon tube containing the fluidic architecture to be used in a drug screen (Fig. 3 c(i)). In this screening the selected separating fluids are mixed with surfactant: Span 80 (sorbitan monooleate), Abil EM90, and Abil EM180 (Cetyl PEG/PPG-10/1 Dimethicone). A tube filled with fluorocarbon HFE-7500 was dipped successively into fluids contained in different wells in a 96-well plate; using a flow rate of $2-5 \mathrm{ml} / \mathrm{h}$, the tube was dipped successively into cells $(2 \mu \mathrm{l})$, separating fluid \pm surfactant $(1 \mu \mathrm{l})$, and HFE-7500 (5 $\mu \mathrm{l})$. Finally, cells were incubated and viability was assessed as above.

The final biocompatibility test used conditions replicating those found in a drug screen - which involves flow down the tube to drive the merging of drops and delivery of drug to cells. First, the tube was filled with HFE-7500, and - as fluid was withdrawn into the tube - the end was dipped successively into HFE-7500 (to load $5 \mu \mathrm{l}$ ), cells in medium (to load a $1 \mu \mathrm{l}$ drop), separating fluid (to load $200 \mu \mathrm{l}$ ), cells in medium (another $1 \mu \mathrm{l}$ drop), and then HFE-7500 (to load $5 \mu \mathrm{l}$ ). This creates a "train" of aqueous drops; repeating this process generates further trains separated by $5 \mu \mathrm{l}$ carrier fluid.

To test the effect of fluid and surfactant on gene expression, a drop containing Jurkat cells and one containing $0.5 \%(\mathrm{v} / \mathrm{v})$ dimethyl sulfoxide (DMSO) were merged (at least 10 pairs in one tube). The carrier fluid used was HFE-7500, and the separating oil was tetradecane $+0.25 \%$ Span 80 or $5 \mathrm{cSt}$ silicone oil $+0.25 \%$ Abil EM180. Five drops were ejected from the tube immediately after loading and each was put into separate Eppendorf tubes containing $12 \mu \mathrm{l}$ "CellsDirect resuspension and lysis buffer" (CellsDirectTM; Life Technologies). The remaining drops in the tube were incubated at $37^{\circ} \mathrm{C}, 5 \% \mathrm{CO}_{2}$ for $4 \mathrm{~h}$ before being ejected individually into lysis buffer. This time was chosen because cells respond to one of the drugs used over this period (Diehn et al. 2002). As a control, $100 \mu \mathrm{l}$ cells were plated in a well in a 96-well plate. $2 \mu \mathrm{l}$ samples were taken from the plate after incubation for 0 and $4 \mathrm{~h}$ and mixed with lysis buffer following the same procedure used with samples from the drops-indrops. Samples from both drops-in-drops and the control were lysed for $10 \mathrm{~min}$ at $75^{\circ} \mathrm{C}$. The level of $5 \mathrm{~S}$ rRNA in each sample was assessed using qRT-PCR (PCR cycles were $50^{\circ} \mathrm{C}$ for $20 \mathrm{~min}, 95^{\circ} \mathrm{C}$ for $5 \mathrm{~min}$, and 40 cycles at $95^{\circ} \mathrm{C}$ for $15 \mathrm{~s}+60^{\circ} \mathrm{C}$ for $30 \mathrm{~s}$ ).

\subsection{Proof-of-principle drug screening}

To demonstrate the inhibition and activation of gene expression in Jurkat cells, the following drugs were used: $100 \mu \mathrm{M} 5$, 6-dichloro-1- $\beta$-D-ribofuranosyl-benzimidazole (DRB) as inhibitor, and $1 \mu \mathrm{g} / \mathrm{ml}$ ionomycin $+62.5 \mathrm{ng} / \mathrm{ml}$ phorbol $12-$ myristate 13-acetate (PMA) as activator. Jurkat cells and drugs or $0.5 \%(\mathrm{v} / \mathrm{v})$ DMSO (as control) were taken into the tube using the same method as the previous test. The carrier fluid was HFE-7500 and the separating oil was 5-cSt silicone oil $+0.25 \%$ Abil EM180. After incubation for $4 \mathrm{~h}$, each sample was ejected into $12 \mu \mathrm{l}$ lysis buffer, and treated as for the previous test. Levels of c-MYC mRNA and IL2 mRNA were also assessed using the $\Delta \Delta \mathrm{Ct}$ qRT-PCR method (Livak and Schmittgen 2001) and RT-PCR plus gel electrophoresis, respectively.

\section{Results and discussion}

\subsection{Effects of tetradecane plus Span 80 on viability}

HFE-7500 plus tetradecane/Span 80 plus growth medium had surface tensions satisfying the requirements of the Neumann triangle. When $0.25 \%$ Span 80 (weight/ weight) - an oil-soluble surfactant that significantly reduces the oil-media interfacial tension from 17.7 to $\sim 1.9$ $\mathrm{mN} / \mathrm{m}$ ) - is added to tetradecane, it has little effect on the interfacial tension between HFE-7500 and tetradecane. As this combination had a particularly suitable alignment of interfacial tensions for use in our assay, and the fluids had previously been used for applications in biology (El Debs et al. 2012; Gu et al. 2011; $\mathrm{Hu}$ et al. 2015; Li et al. 2014; Martin et al. 2003; Schoeman et al. 2014), we explored its biocompatibility.

In our three-phase system, the carrier fluid HFE-7500 engulfs tetradecane and does not contact cells directly; therefore, the main fluids that might affect cell viability are tetradecane and Span 80, and their effects were investigated in two steps. First, as a quick screen, we incubated cells under a layer of tetradecane (with and without Span 80 ) in a 96-well plate. Viability (assess using trypan-blue exclusion) was $>90 \%$ on exposure for $6 \mathrm{~h}$ to tetradecane, either on its own or with $0.25 \%$ or $1 \%$ Span 80 . We then examined effects using the drops-in-drops structure in a tube, with and without drop merging. $0.25 \%$ Span 80 was used as the minimum amount of surfactant in tetradecane that facilitated a reliable merging. There was no significant impact of merging on cell viability (Fig. 2 b) using a level of $80 \%$ as a cut-off - a level that has been used in previous studies ( $\mathrm{Du}$ et al. 2013; Qu et al. 2012; Sgro et al. 2007). 
We then assessed levels of 5S rRNA in cells in drops-in-drops before and after $4 \mathrm{~h}$ incubation in the tube (using qRT-PCR). We first tested if loading and then immediately ejecting drops out of the tube affected cell number (and so 5S rRNA levels); it did not (in Fig. $2 \mathrm{~d}$ ' 0 h', cycle numbers for 'control' and 'dropsin-drops' are comparable). However, after incubation in the drops for $4 \mathrm{~h}$, levels fell (in Fig. $2 \mathrm{~d}$ ' $4 \mathrm{~h}$ ', more PCR cycles are required for detection). This result points to a deterioration in cell function. Therefore, we screened other fluids and surfactants for their potential use in our approach.

\subsection{Screening fluids for effects on viability}

To explore alternative fluid/surfactant combinations that might be used to merge drops, we next listed the fluids/ surfactants that had been used previously with mammalian cells in droplet-based microfluidics (Table 1). In our three-phase system, one fluid must be cell-growth medium, and the second is likely to be either HFE-7500 or FC-40 (i.e., the two fluorocarbons used most frequently to carry aqueous drops in microfluidic systems). Here, we note that HFE-7500 stably maintains the desired architecture of drops-in-drops better than FC-40.
The third fluid has to be immiscible with fluorocarbon and water - and so probably a hydrocarbon, silicone oil, or vegetable oil. Addition of surfactants to this third fluid allows interfacial tensions to be tuned to satisfy the requirements of the Neumann triangle. However, surfactants are usually toxic to cells, and so the challenge is finding an appropriate combination of biocompatible fluids and surfactants.

To find which combinations might be appropriate, biocompatibility was assessed in several steps. First, two fluorocarbons and seven separating oil candidates without surfactant were screened using Jurkats and EL4 cells in a 96-well plate. Viability was quantified after incubation for 24 and 48 h (Fig. 3 a). As dodecane and olive oil gave less than $50 \%$ viability after $24 \mathrm{~h}$ (with a further reduction after $48 \mathrm{~h}$ ), they were excluded from future tests.

The second test focused on the separating oil, leaving 5 candidates: silicone oil AR 20 ('AR 20'), 5-cSt silicone oil ('silicone oil'), mineral oil, tetradecane and hexadecane. Here the final environment was simulated using only two phases, the separating oil and cells in the aqueous phase. In the smaller volume where the surface-to-volume ratio is higher than in the first step, cells prove to be more sensitive as toxic effects were

Table 1 Fluids and surfactants previously used in drop-based microfluidics with mammalian cells

\begin{tabular}{|c|c|c|}
\hline Fluid & Surfactant & Cell type \\
\hline \multicolumn{3}{|c|}{ Fluorinated fluids } \\
\hline \multirow[t]{2}{*}{ FC-40 } & PEG-PFPE block copolymer & $\begin{array}{l}\text { 2C6 hybridoma (Koster et al. 2008), human U937 (Joensson et al. 2009), Chinese Hamster Ovary } \\
\text { (Chen et al. 2011), human PC3, Raji B lymphocytes (Eastburn et al. 2013), } \\
\text { HL60 (Edd et al. 2008), HEK293T (Juul et al. 2011), K562, U87 (Mongersun et al. 2016) }\end{array}$ \\
\hline & $\begin{array}{l}\text { DMP-PFPE block } \\
\text { copolymer }\end{array}$ & HEK293T, Jurkat (Clausell-Tormos et al. 2008), Red blood cells (Abbyad et al. 2011; Abbyad et al. 2010) \\
\hline HFE-7500 & PEG-PFPE block copolymer & $\begin{array}{l}\text { MDA-MB-231, PC9 (Ng et al. 2016), Her2 hybridoma (Hu et al. 2015), RAW } 264.7 \text { (Fischer et al. 2015), } \\
\text { mouse ES (Klein et al. 2015), K-562 (Klein et al. 2015; Ng et al. 2016) }\end{array}$ \\
\hline FC-3283 & Perfluorooctanol (PFO) & Red blood cells (Kline et al. 2008), human periosteal cells (Srisa-Art et al. 2009) \\
\hline \multicolumn{3}{|c|}{ Hydrocarbon/silicone/vegetable oils } \\
\hline Hexadecane & Span 80 & Chinese Hamster Ovary (Zhan et al. 2009), mouse myeloma cells (Kemna et al. 2013) \\
\hline Tetradecane & Span 80 & PC12 (Gu et al. 2011), HeLa, CCRF-CEM, Ramos (Li et al. 2014) \\
\hline \multirow[t]{3}{*}{ Mineral oil } & Abil EM90 & MDCK (Mary et al. 2011) \\
\hline & Span 80 & $\begin{array}{l}\text { Jurkat, red blood cells (Chabert and Viovy 2008), Chinese Hamster Ovary (Hufnagel et al. 2009), } \\
\text { leukemia cells (Sun et al. 2011), PC3 (Konry et al. 2011), human breast cancer cells }\end{array}$ \\
\hline & Abil EM90 + Span 80 & PC9 (Jing et al. 2015) \\
\hline \multirow[t]{2}{*}{ Silicone oil } & - & HeLa (Xiao et al. 2010) \\
\hline & Span 80 & Mouse B lymphocytes (Sgro et al. 2007) \\
\hline Soybean oil & - & Mouse mast cells and B lymphocytes (He et al. 2005) \\
\hline Oleic acid & - & HeLa (Tan et al. 2006) \\
\hline
\end{tabular}


Fig. 3 Effects of different fluids on viability of Jurkats and EL4. (a) Assay using an over- or under-lay in a 96-well plate $(150 \mu$ test fluid $+150 \mu \mathrm{l}$ cells). (i) Cartoon illustrating approach (layers inverted, depending on density). (ii-iii) Viability after incubation with different fluids. Dodecane and olive oil gave poor viability, and so were not used subsequently. (b) Assay using 1- $\mu$ l drops in a two-phase system in a tube. (i) Cartoon illustrating approach. (ii-iii) Viability after incubation with different fluids. Mineral oil and silicone oil AR 20 advanced to the next screening round. (c) Assay using 3-phase system. (i-ii) Viability of Jurkats assessed at different times using a static 3-phase system in a tube. $2 \mu \mathrm{l}$ aqueous drops were engulfed in the separating oil indicated, which - in turn - was engulfed in HFE-7500. (d) Gene expression test using selected fluid/surfactant combination. (i) Cartoon illustrating approach (HFE-7500 as carrier, 5-cSt silicone oil + $0.25 \%$ Abil EM180 as separating oil). (ii) $5 \mathrm{~S}$ rRNA levels (assessed using qRT PCR; a low cycle number reflects a high level). After 4-h incubation, levels in cells in drops-in-drops are comparable to those in cells grown conventionally (a)

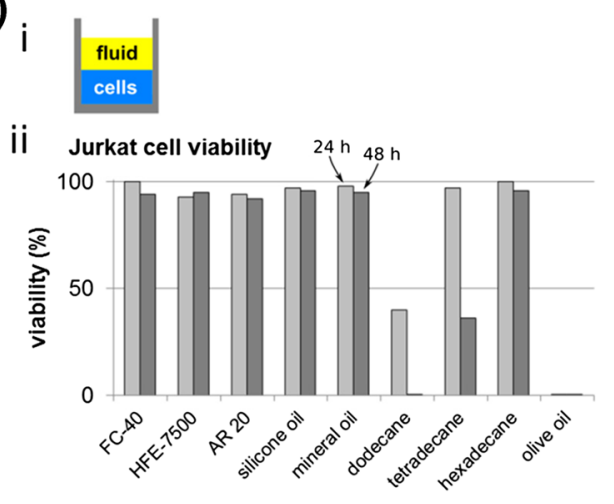

iii EL4 cell viability

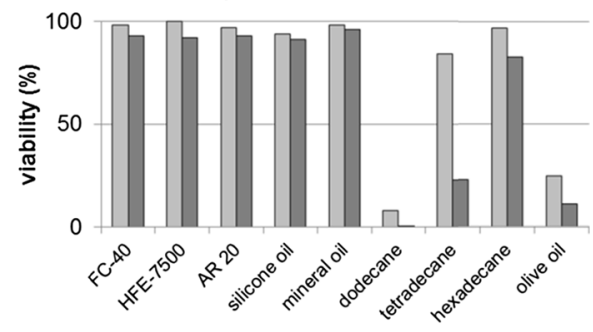

(b)

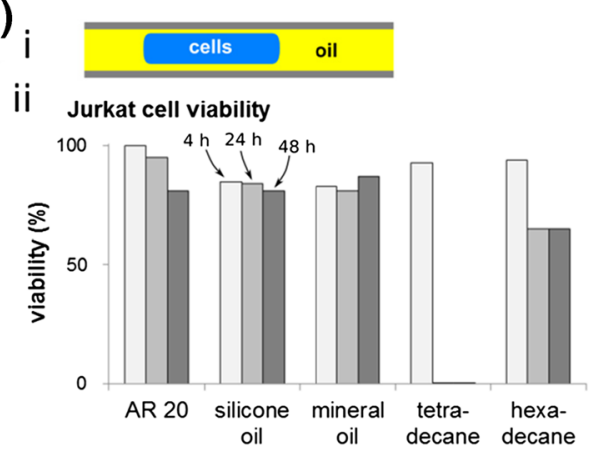

(c)

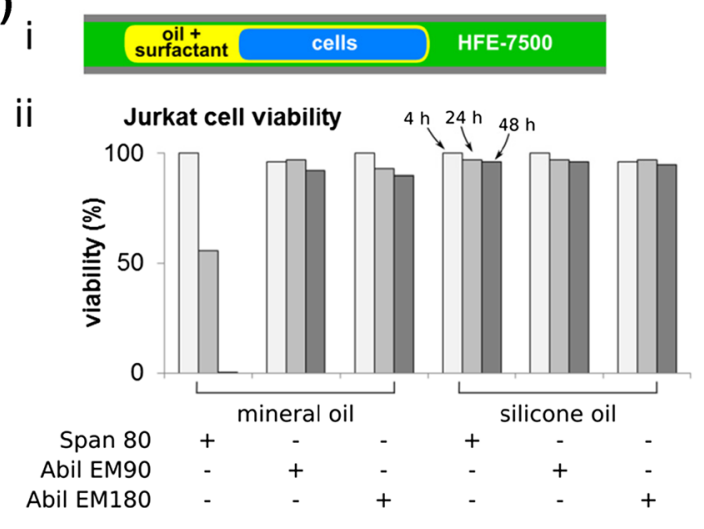

iii EL4 cell viability

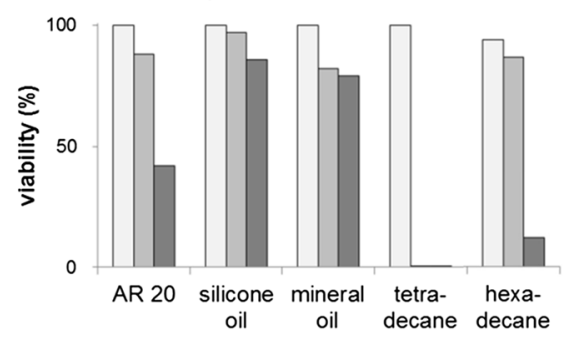

(d)

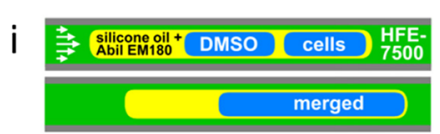

ii

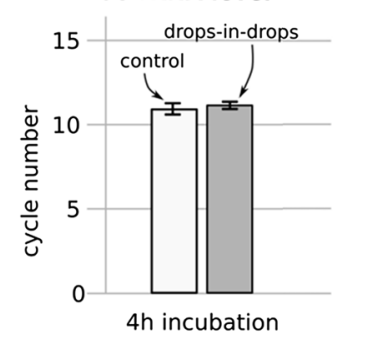

observed sooner (Fig. 3 b). All separating oils gave high viability during a short incubation of $4 \mathrm{~h}$, but after 24 and $48 \mathrm{~h}$ some toxicity became apparent. For example, earlier we saw $\sim 80 \%$ viability in tetradecane plus Span 80 after a 4-h incubation (Fig. 2 b); here, viability was higher without surfactant, but complete cell death was observed after $24 \mathrm{~h}$ (Fig. 3b). For the next step, only fluids giving high viability after the longest incubation period (i.e., mineral oil and 5-cSt silicone oil) were included, even though drug screening would be carried over a shorter period.

In the third test, 5-cSt silicone oil and mineral oil were tested for their suitability. Two $1-\mu l$ drops of cell culture media were initially separated by $200 \mathrm{nl}$ oil in HFE-7500. First, a $1 \%$ weight-to-weight surfactant in oil was used, followed by serial dilution down to the lowest concentration giving reliable drop merging. As the two oils have different properties, different surfactant concentrations allow merging (e.g., $0.5 \%$ in mineral oil, and $0.25 \%$ in 5 -cSt silicone oil). Next, Jurkats were incubated in a Teflon tube in $2-\mu 1$ drops engulfed in separating fluid/surfactant (and HFE-7500 as the carrier), and viability measured (Fig. 3 c). Mineral oil + Span 80 proved particularly toxic. 5 -cSt silicone oil with all surfactants gave good viability, but Abil EM180 was selected as the surfactant as it maintained drop architecture best during incubation.

As a final step, the effects of 5-cSt silicone oil $+0.25 \%$ Abil EM180 in a 3-phase system on levels of 5S rRNA were tested; cells in drops-in-drops behave like controls (Fig. 3 d). 
(a)

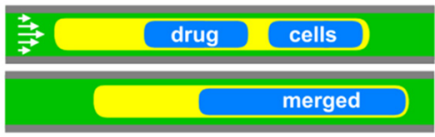

(c)

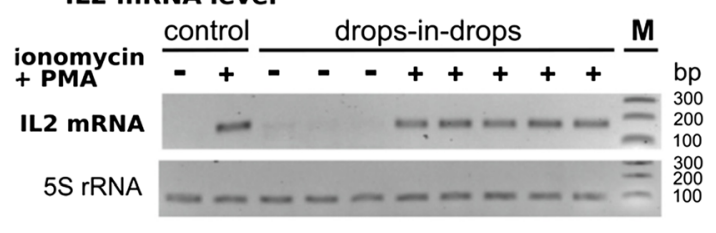

(b)

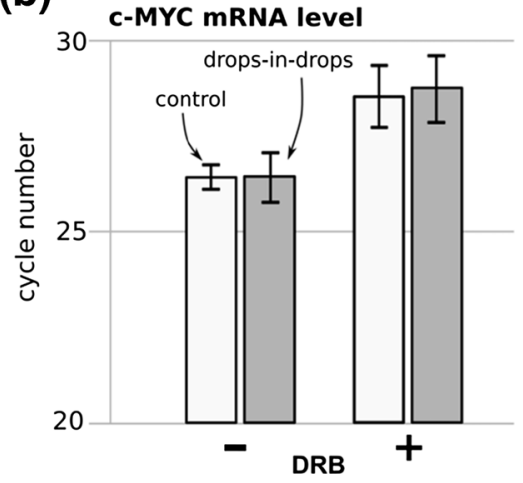

Fig. 4 Jurkat cells in drops-in-drops respond to drugs like controls grown conventionally. (a) Schematic illustration of the drug screening (HFE-7500 as carrier, 5-cSt silicone oil $+0.25 \%$ Abil EM180 as separating oil). (b) Effects of DRB on c-MYC mRNA levels (assessed using qRT-PCR). DRB increases cycle number, indicating it reduces mRNA levels; conventional ('control') cells behave like those in drops-in-drops. (c)

\subsection{A proof-of-principle drug screen}

Having established which combination of fluids to use (i.e., HFE-7500, 5-cSt silicone oil + 0.25\% Abil EM180, medium containing cells), we performed a proof-of-concept drug screen (Feuerborn et al. 2015; supplementary information). DRB (6-dichloro-1- $\beta$-D-ribofuranosyl-benzimidazole) is a general transcriptional inhibitor, and - when a drop containing it is merged with another containing Jurkats as in Fig. 4a, levels of c-MYC mRNA (assessed by qRT-PCR) are repressed (in Fig. 4b, more cycles are required, indicative of depression of levels). A drug pair - ionomycin plus phorbol 12-myristate 13-acetate (PMA) - initiate an inflammatory response, and this leads to an increase in levels of interleukin-2 (IL2) mRNA; when a drop containing the pair is merged with another containing cells, levels of IL2 mRNA (assessed using RT-PCR and gel electrophoresis) increase (in Fig. 4c, the band indicative of IL2 mRNA appears). In both cases, cells in drops-in-drops behave like controls grown conventionally (Fig. 4a and b). These experiments showed that HFE-7500 and 5-cSt silicone oil $+0.25 \%$ Abil EM1 80 can deliver both biocompatibility and the interfacial tensions necessary for the merging of drops in a Teflon tube - and so this combination is suitable for drug screening using our assay.

\section{Conclusion}

Different fluids and surfactants commonly used in drop-based microfluidic system have been screened for their biocompatibilities. Genetic analysis showed that cell viability alone was a less reliable indicator of fluid and surfactant biocompatibility. For drops-in-drops applications involving mammalian cells, HFE-7500 as the carrier fluid and 5-cSt silicone oil $+0.25 \%$ Abil EM180 as the separating oil showed
Effects of ionomycin + PMA on IL2 mRNA levels (assessed using RTPCR and gel electrophoresis). 171-bp band indicative of IL2 mRNA is only seen after treatment with ionomycin and PMA; conventional ('control') cells behave like those in drops-in-drops. M: 100-, 200-, 300-bp markers. This Figure was redrawn using data from supplementary information in reference (Feuerborn et al. 2015)

comparable performance in gene expression tests $(4 \mathrm{~h}$ incubation time) to the conventional method. Therefore this fluid and surfactant combination is recommended for drug screening. Further works need to be done to assess cell proliferation in the tube for longer time periods using these and/or other fluids. Although here we assume that the incompatibility comes from the fluid and surfactant which are in contact with cell media, there might also be contributions from the tube material (Jiang et al. 2015; Panaro et al. 2004); hence tube biocompatibility and alternative tube materials could also be explored in future works. Finally we suggest that results obtained with many fluid and surfactant combinations and cellbased microfluidics should be interpreted with caution.

Acknowledgements We thank Oreste Acuto for Jurkat cells, and the Medical Research Council (grant MR/K010867/1), the Indonesian Endowment Fund for Education (LPDP), the 7th Framework Marie Curie Career Integration grant contract no. 333848, and University of Oxford John Fell Fund for support.

Open Access This article is distributed under the terms of the Creative Commons Attribution 4.0 International License (http:// creativecommons.org/licenses/by/4.0/), which permits unrestricted use, distribution, and reproduction in any medium, provided you give appropriate credit to the original author(s) and the source, provide a link to the Creative Commons license, and indicate if changes were made.

\section{References}

P. Abbyad, P. L. Tharaux, J. L. Martin, C. N. Baroud, A. Alexandrou, Sickling of red blood cells through rapid oxygen exchange in microfluidic drops. Lab. Chip. 10, 2505-2512 (2010). Doi:10.1039/c004390g

P. Abbyad, R. Dangla, A. Alexandrou, C. N. Baroud, Rails and anchors: guiding and trapping droplet microreactors in two dimensions. Lab. Chip. 11, 813-821 (2011). Doi:10.1039/c0lc00104j

J. C. Baret, Surfactants in droplet-based microfluidics. Lab. Chip. 12, 422-433 (2012). Doi:10.1039/c1lc20582j 
J. Bico, D. Quéré, Liquid trains in a tube. Europhys. Lett. 51, 546-550 (2000)

F. P. Bretherton, The motion of long bubbles in tubes. J. Fluid. Mech. 10, 166-168 (1961)

M. Chabert, J. L. Viovy, Microfluidic high-throughput encapsulation and hydrodynamic self-sorting of single cells. Proc. Nat.l Acad. Sc. U. S. A 105, 3191-3196 (2008). Doi:10.1073/pnas.0708321105

D. L. Chen, L. Li, S. Reyes, D. N. Adamson, R. F. Ismagilov, Using threephase flow of immiscible liquids to prevent coalescence of droplets in microfluidic channels: criteria to identify the third liquid and validation with protein crystallization. Langmuir. 23, 2255-2260 (2007)

F. Chen, Y. Zhan, T. Geng, H. Lian, P. Xu, C. Lu, Chemical transfection of cells in picoliter aqueous droplets in fluorocarbon oil. Anal. Chem. 83, 8816-8820 (2011). Doi:10.1021/ac2022794

K. Churski, T. S. Kaminski, S. Jakiela, W. Kamysz, W. Baranska-Rybak, D. B. Weibel, P. Garstecki, Rapid screening of antibiotic toxicity in an automated microdroplet system. Lab. Chip. 12, 1629-1637 (2012). Doi:10.1039/c2lc21284f

J. Clausell-Tormos et al., Droplet-based microfluidic platforms for the encapsulation and screening of mammalian cells and multicellular organisms. Chem. Biol. 15, 427-437 (2008). Doi:10.1016/j. chembiol.2008.04.004

M. Diehn et al., Genomic expression programs and the integration of the CD82 costimulatory signal in T cell activation. Proc. Natl. Acad. Sci. 99, 11796-11801 (2002). Doi:10.1073/pnas.242607799

P. S. Dittrich, A. Manz, Lab-on-a-chip: microfluidics in drug discovery. Nat. Rev. Drug Discov. 5, 210-218 (2006). Doi:10.1038/nrd1985

O. J. Dressler, R. M. Maceiczyk, S. I. Chang, A. J. deMello, Dropletbased microfluidics: enabling impact on drug discovery. J. Biomol. Screen. 19, 483-496 (2014). Doi:10.1177/1087057113510401

G. S. Du, J. Z. Pan, S. P. Zhao, Y. Zhu, J. M. den Toonder, Q. Fang, Cellbased drug combination screening with a microfluidic droplet array system. Anal. Chem. 85, 6740-6747 (2013). Doi:10.1021/ac400688f

D. J. Eastburn, A. Sciambi, A. R. Abate, Ultrahigh-throughput mammalian single-cell reverse-transcriptase polymerase chain reaction in microfluidic drops. Anal. Chem. 85, 8016-8021 (2013). Doi:10.1021/ac402057q

J. F. Edd, D. Di Carlo, K. J. Humphry, S. Koster, D. Irimia, D. A. Weitz, M. Toner, Controlled encapsulation of single-cells into monodisperse picolitre drops. Lab Chip 8, 1262-1264 (2008). Doi:10.1039 b805456h

B. El Debs, R. Utharala, I. V. Balyasnikova, A. D. Griffiths, C. A. Merten, Functional single-cell hybridoma screening using droplet-based microfluidics. Proc. Natl. Acad. Sci. U. S. A. 109, 11570-11575 (2012). Doi:10.1073/pnas.1204514109

A. Feuerborn, A. Prastowo, P. R. Cook, E. Walsh, Merging drops in a Teflon tube, and transferring fluid between them, illustrated by protein crystallization and drug screening. Lab. Chip. 15, 3766-3775 (2015). Doi:10.1039/c5lc00726g

G. S. Fiorini, D. T. Chiu, Disposable microfluidic devices: fabrication, function, and application. BioTechniques. 38, 429-446 (2005)

A. E. Fischer et al., A high-throughput drop microfluidic system for virus culture and analysis. J. Virol. Methods. 213, 111-117 (2015). Doi:10.1016/j.jviromet.2014.12.003

J. Friend, L. Yeo, Fabrication of microfluidic devices using polydimethylsiloxane. Biomicrofluidics. 4 (2010). Doi:10.1063/1.3259624

Y. Gao, P. Li, D. Pappas, A microfluidic localized, multiple cell culture array using vacuum actuated cell seeding: integrated anticancer drug testing. Biomed. Microdevices. 15, 907-915 (2013). Doi:10.1007 /s10544-013-9779-3

Z. Gong et al., Drug effects analysis on cells using a high throughput microfluidic chip. Biomed. Microdevices. 13, 215-219 (2011). Doi:10.1007/s10544-010-9486-2

S. Q. Gu, Y. X. Zhang, Y. Zhu, W. B. Du, B. Yao, Q. Fang, Multifunctional picoliter droplet manipulation platform and its application in single cell analysis. Anal. Chem. 83, 7570-7576 (2011). Doi:10.1021/ac201678g

J. Guzowski, P. M. Korczyk, S. Jakiela, P. Garstecki, The structure and stability of multiple micro-droplets. Soft. Matter. 8, 7269 (2012). Doi: $10.1039 / \mathrm{c} 2 \mathrm{sm} 25838 \mathrm{~b}$

A. S. Hansen, N. Hao, E. K. O'Shea, High-throughput microfluidics to control and measure signaling dynamics in single yeast cells. Nat. Protoc. 10, 1181-1197 (2015). Doi:10.1038/nprot.2015.079

M. He, J. S. Edgar, G. D. M. Jeffries, R. M. Lorenz, P. Shelby, D. T. Chiu, Selective encapsulation of single cells and subcellular organelles into picoliter-and-femtoliter-volume droplets. Anal. Chem. 77, 1539-1544 (2005)

B. Hong, P. Xue, Y. Wu, J. Bao, Y. J. Chuah, Y. Kang, A concentration gradient generator on a paper-based microfluidic chip coupled with cell culture microarray for high-throughput drug screening. Biomed. Microdevices. 18, 21 (2016). Doi:10.1007/s10544-016-0054-2

H. Hu, D. Eustace, C. A. Merten, Efficient cell pairing in droplets using dual-color sorting. Lab. Chip. (2015). Doi:10.1039/c5lc00686d

M. Huang et al., Microfluidic screening and whole-genome sequencing identifies mutations associated with improved protein secretion by yeast. Proc. Natl. Acad. Sci. U. S. A. 112, E4689-E4696 (2015). Doi:10.1073/pnas.1506460112

H. Hufnagel, A. Huebner, C. Gulch, K. Guse, C. Abell, F. Hollfelder, An integrated cell culture lab on a chip: modular microdevices for cultivation of mammalian cells and delivery into microfluidic microdroplets. Lab. Chip. 9, 1576-1582 (2009). Doi:10.1039 /b821695a

X. Jiang, R. E. Jeffries, M. A. Acosta, A. P. Tikunov, J. M. Macdonald, G. M. Walker, M. P. Gamcsik, Biocompatibility of Tygon(R) tubing in microfluidic cell culture. Biomed. Microdevices. 17, 20 (2015). Doi:10.1007/s10544-015-9938-9

T. Jing, R. Ramji, M. E. Warkiani, J. Han, C. T. Lim, C. H. Chen, Jetting microfluidics with size-sorting capability for single-cell protease detection. Biosensors \& bioelectronics 66, 19-23 (2015). Doi:10.1016/j.bios.2014.11.001

H. N. Joensson, M. L. Samuels, E. R. Brouzes, M. Medkova, M. Uhlen, D. R. Link, H. Andersson-Svahn, Detection and analysis of lowabundance cell-surface biomarkers using enzymatic amplification in microfluidic droplets. Angew. Chem. 48, 2518-2521 (2009). Doi:10.1002/anie.200804326

S. Juul, Y.-P. Ho, J. Koch, F. F. Andersen, M. Stougaard, K. W. Leong, B. R. Knudsen, Detection of single enzymatic events in rare or single cells using microfluidics. ACS. Nano. 5, 8305-8310 (2011)

L. Kang, B. G. Chung, R. Langer, A. Khademhosseini, Microfluidics for drug discovery and development: from target selection to product lifecycle management. Drug. Discov. Today. 13, 1-13 (2008). Doi:10.1016/j.drudis.2007.10.003

R. A. Kellogg, R. Gomez-Sjoberg, A. A. Leyrat, S. Tay, High-throughput microfluidic single-cell analysis pipeline for studies of signaling dynamics. Nat. Protoc. 9, 1713-1726 (2014). Doi:10.1038 /nprot.2014.120

E. W. Kemna, L. I. Segerink, F. Wolbers, I. Vermes, A. van den Berg, Label-free, high-throughput, electrical detection of cells in droplets. Analyst. 138, 4585-4592 (2013). Doi:10.1039/c3an00569k

A. M. Klein et al., Droplet barcoding for single-cell transcriptomics applied to embryonic stem cells. Cell. 161, 1187-1201 (2015). Doi:10.1016/j.cell.2015.04.044

T. R. Kline, M. K. Runyon, M. Pothiawala, R. F. Ismagilov, ABO, D blood typing and subtyping using plug-based microfluidics. Anal. Chem. 80, 6190-6197 (2008)

T. Konry, I. Smolina, J. M. Yarmush, D. Irimia, M. L. Yarmush, Ultrasensitive detection of low-abundance surface-marker protein using isothermal rolling circle amplification in a microfluidic nanoliter platform. Small. 7, 395-400 (2011). Doi:10.1002 /smll.201001620 
S. Koster et al., Drop-based microfluidic devices for encapsulation of single cells. Lab. Chip. 8, 1110-1115 (2008). Doi:10.1039 /b802941e

L. Li, Q. Wang, J. Feng, L. Tong, B. Tang, Highly sensitive and homogeneous detection of membrane protein on a single living cell by aptamer and nicking enzyme assisted signal amplification based on microfluidic droplets. Anal. Chem. 86, 5101-5107 (2014). Doi:10.1021/ac500881p

W. Liu, H. J. Kim, E. M. Lucchetta, W. Du, R. F. Ismagilov, Isolation, incubation, and parallel functional testing and identification by FISH of rare microbial single-copy cells from multi-species mixtures using the combination of chemistrode and stochastic confinement. Lab. Chip. 9, 2153-2162 (2009). Doi:10.1039/b904958d

K. J. Livak, T. D. Schmittgen, Analysis of relative gene expression data using real-time quantitative PCR and the 2(-Delta Delta $\mathrm{C}(\mathrm{T})$ ) method. Methods. 25, 402-408 (2001). Doi:10.1006 /meth.2001.1262

K. Martin et al., Generation of larger numbers of separated microbial populations by cultivation in segmented-flow microdevices. Lab. Chip. 3, 202-207 (2003). Doi:10.1039/b301258c

P. Mary, L. Dauphinot, N. Bois, M. C. Potier, V. Studer, P. Tabeling, Analysis of gene expression at the single-cell level using microdroplet-based microfluidic technology. Biomicrofluidics. 5, 24109 (2011). Doi:10.1063/1.3596394

L. Mazutis, J. Gilbert, W. L. Ung, D. A. Weitz, A. D. Griffiths, J. A. Heyman, Single-cell analysis and sorting using droplet-based microfluidics. Nat. Protoc. 8, 870-891 (2013). Doi:10.1038 Inprot.2013.046

O. J. Miller et al., High-resolution dose-response screening using dropletbased microfluidics. Proc. Natl. Acad. Sci. U. S. A. 109, 378-383 (2012). Doi:10.1073/pnas.1113324109

A. Mongersun, I. Smeenk, G. Pratx, P. Asuri, P. Abbyad, Droplet microfluidic platform for the determination of single-cell lactate release. Anal. Chem. 88, 3257-3263 (2016). Doi:10.1021/acs. analchem. 5 b04681

E. X. Ng, M. A. Miller, T. Jing, C. H. Chen, Single cell multiplexed assay for proteolytic activity using droplet microfluidics. Biosens. Bioelectron. 81, 408-414 (2016). Doi:10.1016/j.bios.2016.03.002

N. J. Panaro, X. J. Lou, P. Fortina, L. J. Kricka, P. Wilding, Surface effects on PCR reactions in multichip microfluidic platforms. Biomed. Microdevices 6, 75-80 (2004)

Z. Pang, A. Al-Mahrouki, M. Berezovski, S. N. Krylov, Selection of surfactants for cell lysis in chemical cytometry to study proteinDNA interactions. Electrophoresis. 27, 1489-1494 (2006). Doi:10.1002/elps.200500732

M. A. Partearroyo, H. Ostolaza, F. M. Goni, E. Barbera-Guillem, Surfactant-induced cell toxicity and cell lysis - a study using B12 melanoma cells. Biochem. Pharmacol. 40, 1323-1328 (1990)
B. Qu, Y. J. Eu, W. J. Jeong, D. P. Kim, Droplet electroporation in microfluidics for efficient cell transformation with or without cell wall removal. Lab. Chip. 12, 4483-4488 (2012). Doi:10.1039/c2 lc40360a

R. Rodriguez-Rodriguez, X. Munoz-Berbel, S. Demming, S. Buttgenbach, M. D. Herrera, A. Llobera, Cell-based microfluidic device for screening anti-proliferative activity of drugs in vascular smooth muscle cells. Biomed. Microdevices. 14, 1129-1140 (2012). Doi:10.1007/s10544-012-9679-y

E. K. Sackmann, A. L. Fulton, D. J. Beebe, The present and future role of microfluidics in biomedical research. Nature. 507, 181-189 (2014). Doi:10.1038/nature13118

R. M. Schoeman, E. W. Kemna, F. Wolbers, A. van den Berg, Highthroughput deterministic single-cell encapsulation and droplet pairing, fusion, and shrinkage in a single microfluidic device. Electrophoresis. 35, 385-392 (2014). Doi:10.1002/elps.201300179

A. E. Sgro, P. B. Allen, D. T. Chiu, Thermoelectric manipulation of aqueous droplets in microfluidic devices. Anal. Chem. 79, 48454851 (2007)

M. Srisa-Art, I. C. Bonzani, A. Williams, M. M. Stevens, A. J. deMello, J. B. Edel, Identification of rare progenitor cells from human periosteal tissue using droplet microfluidics. Analyst. 134, 2239-2245 (2009). Doi:10.1039/b910472k

M. Sun, S. S. Bithi, S. A. Vanapalli, Microfluidic static droplet arrays with tuneable gradients in material composition. Lab. Chip. 11, 39493952 (2011). Doi:10.1039/c1lc20709a

Y.-C. Tan, K. Hettiarachchi, M. Siu, Y.-R. Pan, A. P. Lee, Controlled microfluidic encapsulation of cells, proteins, and microbeads in lipid vesicles. J. Am. Chem. Soc. 128, 5656-5658 (2006)

M. Tea, M. Z. Michael, H. M. Brereton, K. A. Williams, Stability of small non-coding RNA reference gene expression in the rat retina during exposure to cyclic hyperoxia. Mol. Vis. 19, 501-508 (2013)

J. H. Tsui, W. Lee, S. H. Pun, J. Kim, D. H. Kim, Microfluidics-assisted in vitro drug screening and carrier production. Adv. Drug. Deliv. Rev. 65, 1575-1588 (2013). Doi:10.1016/j.addr.2013.07.004

E. Walsh, A. Feuerborn, P. R. Cook, Formation of droplet interface bilayers in a Teflon tube. Sci Rep 6, 34355 (2016). Doi:10.1038 /srep34355

K. Xiao, M. Zhang, S. Chen, L. Wang, D. C. Chang, W. Wen, Electroporation of micro-droplet encapsulated HeLa cells in oil phase. Electrophoresis. 31, 3175-3180 (2010). Doi:10.1002 /elps.201000155

Z. T. F. Yu et al., Integrated microfluidic devices for combinatorial cellbased assays. Biomed. Microdevices. 11, 547-555 (2009). Doi:10.1007/s10544-008-9260-x

Y. Zhan, J. Wang, N. Bao, C. Lu, Electroporation of cells in microfluidic droplets. Anal. Chem. 81, 2027-2031 (2009) 